\title{
Anterior eye development in the brown anole, Anolis sagrei
}

Ashley M. Rasys ${ }^{1}$, Shana H. Pau², Katherine E. Irwin ${ }^{1}$, Sherry Luo², Douglas B. Menke², and James D. Lauderdale ${ }^{1,3}$

${ }^{1}$ Department of Cellular Biology, The University of Georgia, Athens, GA 30602, USA; ${ }^{2}$ Department of Genetics, The University of Georgia, Athens, GA 30602, USA; ${ }^{3}$ Neuroscience Division of the Biomedical and Health Sciences Institute, The University of Georgia, Athens, GA 30602, USA.

Running title: Anterior eye development in brown anoles

Key words: lizard, lens, cornea, iris, ciliary body, and trabecular meshwork

Corresponding author and person to whom request should be addressed:

James D. Lauderdale

Department of Cellular Biology

University of Georgia

Athens, GA 30602, USA

Ph. 706-542-7433

Fax: 706-542-4271

e-mail: jdlauder@uga.edu

Douglas B. Menke

24 Department of Genetics

25 University of Georgia

26 Athens, GA 30602, USA

27 Ph. 706-542-9557

28 Fax: 706-542-3910

29 e-mail: dmenke@uga.edu

Funding: This work was funded by National Science Foundation awards 1149453 to D.B.M. and 1827647 to D.B.M. and J.D.L. and a Society for Developmental Biology Emerging Models grant to A.M.R. A.M.R. was supported by NIH training grant T32GM007103 and by an ARCS Foundation Scholarship.

Disclosure Statement: The authors have nothing to disclose. The funders of this research had no role in study design, data collection and analysis, decision to publish, or preparation of the manuscript. 
Rasys et al.

Anterior eye development in brown anoles

\section{Abstract}

2 Background: Anterior eye development has been explored in different vertebrate

3 species ranging from fish to mammals. However, missing from this diverse group is a

4 representative of reptiles. A promising candidate to fill this void is the brown anole,

5 Anolis sagrei, which is easily raised in the laboratory and for which genome editing

6 techniques exist. Here we provide a detailed histological analysis of the development of

7 the anterior structures of the eye in A. sagrei, which include the cornea, iris, ciliary body,

8 lens, trabecular meshwork, and sclera ossicles.

Results: Development of the anterior segment in Anoles proceeds as for other

11 vertebrates with the lens forming first followed by the cornea, then the iris, ciliary body,

12 trabecular meshwork, and sclera ossicles. The onset of these latter structures occurs

13 first temporally than nasally. Unlike the eyes of mammals and birds, anoles possess a

14 remarkably thin cornea, flat ciliary body, and a trabecular meshwork that lacks an

15 obvious Schlemm's canal.

17 Conclusions: This study highlights several features present in anoles and represents an

18 important step towards understanding reptile eye development.

\section{Key Findings}

- The anole cornea epithelium is thin, composed mainly of a single basal cell layer.

- The ciliary body lacks a ciliary process.

- Iris and ciliary body formation occur in a spatiotemporal fashion, developing first temporally then nasally.

- The anole trabecular meshwork is composed of a spongiform tissue and lacks a Schlemm's canal. 
Rasys et al.

Anterior eye development in brown anoles

\section{Introduction}

The anatomical structure of the vertebrate eye has been described in diverse species. ${ }^{1-3}$ With a consistency that gave Darwin pause, ${ }^{4}$ the canonical vertebrate eye is composed of cornea, lens, iris, ciliary body, muscle, and retina encased in sclera.

Beginning with Hans Spemann at the start of the twentieth century, decades of experimental work by numerous investigators have revealed much about the mechanisms controlling the formation of structures common to all vertebrate eyes. ${ }^{5-8}$ However, the eye of any given vertebrate is not just an assemblage of common structures. Rather, its construction during development reflects the needs of the user. Consequently, there is rich variation in the structures of the eye between species.

Reptiles are a class of vertebrates with over 10,000 described species and collectively exhibit rich diversity in eye anatomy. ${ }^{1,9}$ Comparative studies between reptiles, birds, mammals and amphibians have the potential to reveal both common features of tetrapod eye development, as well as features that are unique to reptilian species, ${ }^{10}$ but few studies of eye development have been performed in reptiles. This may be due, in part, to challenges in routinely obtaining large numbers of reptile embryos and to the lack of modern genetic and molecular tools that can be used to investigate the genes and pathways involved in reptile eye development.

An emerging system that has recently overcome many of these barriers is the brown anole lizard, Anolis sagrei. This lizard has a relatively short developmental period, going from egg-lay to hatching within a month's time, reproduces weekly and remains reproductively active for several months of the year. ${ }^{11}$ Moreover, genome modification is now possible in these lizards along with the ability to culture embryos for extended periods. ${ }^{12,13}$ Together, these attributes make this lizard an ideal candidate for embryological studies, and we are working to advance the brown anole lizard as a model for investigations of reptilian eye development.

\section{In this, the second of three papers detailing Anolis eye development, we focus on} the anterior structures of the eye. Although there are a few historical reports about the tissues of the anterior segment of the reptilian eye, ${ }^{1,9}$ the work we report here is, to our knowledge, the first to comprehensively examine the development of the lens, cornea, iris, ciliary body, and associated tissues in a reptile. 
Rasys et al.

Anterior eye development in brown anoles

\section{Materials and Methods}

2 Animals

All experimental procedures involving lizards were conducted in accordance with the National Institutes of Health Guide for the Care and Use of Laboratory Animals under protocols approved and overseen by the University of Georgia Institutional Animal Care and Use Committee. Anolis sagrei were maintained in a breeding colony at the University of Georgia following guidelines described by Sanger et al., 2008. ${ }^{14}$ Eggs were collected weekly from natural matings and placed in $100 \times 15 \mathrm{~mm}$ lidded petri dishes containing moist vermiculite and incubated at $28^{\circ} \mathrm{C}$ and $70 \%$ humidity. Both male and female embryos were used for these studies. Adults and hatchlings were euthanized using methods consistent with the American Veterinary Medical Association (AVMA)

12 Guidelines for the Euthanasia of Animals. ${ }^{15,16}$

Staging

14 Embryonic development of Anolis lizards typically takes place over a 30-33 day period, starting with internal fertilization. ${ }^{17}$ Early embryogenesis proceeds within the oviduct. A. sagrei embryos obtained from eggs that were collected after egg-laying were staged as described by Sanger et al., 2008. ${ }^{17}$ Embryos younger than those captured by

18 the Sanger staging series were denoted with the prefix " $P L$ " for pre-laying followed by a number. We describe here $5 \mathrm{PL}$ timepoints, which includes the first few embryonic stages of the Sanger staging series (Sanger St 1-3 correspond to PL 3-5). PL stage

21 embryos were collected from gravid adult females following euthanasia.

Dissection and Histology

23 Lizard embryos were accessed by opening eggs using iris scissors and blunt

24 forceps in 1x phosphate-buffered saline (PBS; $137 \mathrm{mM} \mathrm{NaCl}, 2.7 \mathrm{mM} \mathrm{KCl}, 10 \mathrm{mM}$ $25 \mathrm{Na}_{2} \mathrm{HPO}_{4}, 1.8 \mathrm{mM} \mathrm{KH}_{2} \mathrm{PO}_{4}, \mathrm{pH}$ 7.4). Staged embryos or eyes were fixed in Bouin's

26 Fixative at $4^{\circ} \mathrm{C}$ overnight. Specimens were stored in $70 \% \mathrm{EtOH}$ at 4 degrees. Lithium

27 carbonate was added to 1x PBS washes and 70\% EtOH in Bouin's fixed tissue to

28 facilitate removal of picric acid. Embryos or isolated eyes were embedded in paraffin,

29 sectioned on a microtome, and stained with hematoxylin and eosin (H \& E). ${ }^{18}$

30 Photomosaic images were generated using a KEYENCE BZ-700 microscope with 
Rasys et al.

Anterior eye development in brown anoles

1 Keyence image stitching software. Adobe Photoshop CC (2017.01 release) was used to

2 digitally enhance contrast and adjust white balance of images.

Results

Anterior structures of the adult eye

All of the anterior structures in the adult eye are visible in horizontal section (axial section in the naso-temporal plane) through the ocular globe, and include the cornea, lens, iris, ciliary body, and structures responsible for draining the aqueous humor from the eye (Figure 1). Externally, the cornea is positioned towards the nasal side of the

9 ocular globe, slightly off the optical axis. ${ }^{18}$ Histologically, the cornea is composed of an

10 outer epithelial layer, middle stromal layer, and inner endothelial layer (Figure 1.1a).

11 The epithelial layer is primarily a simple epithelium composed of cells with thick

12 squamous morphology (Figure 1.1a). This contrasts with the stratified corneal epithelia

13 found in the eyes other reptiles, birds and mammals. 1,19-22 The stroma can be divided

14 visually into two layers: an anterior layer adjacent to the corneal epithelium, and a

15 posterior layer that is adjacent to the endothelium. The anterior layer, which we believe

16 to be Bowman's membrane, ${ }^{9}$ exhibits a compact arrangement of collagen fibrils, while

17 the posterior layer has a more relaxed arrangement (Figure 1.1a). Scattered, but

18 typically straddling the midline between these stroma divisions, are presumptive

19 keratocytes. Finally, the endothelial layer of the cornea is composed of a single layer of

20 cells with flattened morphology (Figure 1.1a). We were not able to identify by histology a

21 clearly defined posterior limiting membrane, known as Descemet's layer, separating the

22 stroma from the endothelium. With the exception of Descemet's layer, our histological

23 findings are consistent with the written description provided of the cornea for $A$.

24 lineatopus. ${ }^{9}$ As with other reptiles, birds and mammals, the stroma contributes to most 25 of the corneal thickness. ${ }^{1,19-22}$

26 The gross structure of the lens of adult $A$. sagrei (Figure 1 ) is directly comparable to

27 that previously described for $A$. lineatopus. ${ }^{9}$ The lens, which is soft compared to mouse,

28 rabbit, horse, and human (the mammals for which we have lens data), is elliptical in

29 shape with a smaller center nucleus, larger cortex, and outer epithelium (Figure 1.1;

30 Figure 2). The lens nucleus is defined by the presence of primary lens fiber cells, and 
Rasys et al.

Anterior eye development in brown anoles

1 the cortex is defined by the presence of secondary lens fiber cells. The nucleus and

2 cortex make up the main lens body. The lens epithelium is thicker around the equator

3 where it forms the annular pad, also known as the "Ringwulst" (Figure 1.1; Figure 2).

4 The annular pad is characterized by nucleated fibers and is a feature present in the

5 lenses of many reptiles and birds ${ }^{1,9,23,24}$. Surrounding these structures is a thick lens

capsule (Figure 1.1,b,c). At the anterior face, long thin zonular fibers can be seen anchoring the lens to the ciliary body (Figure 1.2).

8 The iris is a muscular structure that controls the amount of light entering the eye. Prominent notches are visible at approximately 12 o'clock and 7 o'clock (right eye) or 12 o'clock and 5 o'clock (left eye) on the iris face when eyes are viewed externally and in

11 their natural position within the skull. ${ }^{18}$ The length of the iris is broader temporally (the

12 region subtended from 12 to 5 o'clock) than nasally (the region from 5 to 12 o'clock). ${ }^{18}$

13 This asymmetry appears to align the center of the iris aperture with that of the cornea.

14 The iris is closely associated with the lens (Figure 1.2). Histologically, the iris (the pars

15 iridica retinae) is an extension of the ciliary epithelium. It is composed of outer and inner

16 epithelial layers which are thin; individual cell morphology is not easily observed by

17 brightfield microscopy due to the dark pigmentation of these cells. Superficial to these

18 layers is the stroma. The stroma is vascularized, has some pigment granules, and

19 attaches to the sphincter and dilator muscles, which are striated and not smooth (Figure

20 1.2). Strands of iris/uveal tissue, likely the pectinate ligaments, connect the base of the

21 iris to the peripheral cornea/sclera, forming the boundary of the anterior chamber at the

22 iridocorneal angle.

23 Located between the iris and ora serrata, the ciliary body is an annular structure

24 located at the equator of the lens. In section, the ciliary body is linear rather than folded

25 like in mammals and birds (Figure 1.2). The ciliary body (the pars ciliaris retinae), like

26 the iris, is comprised of an outer and inner epithelial cell layers. The outer epithelium is

27 heavily pigmented and is contiguous with the pigmented epithelium of the iris on one

28 side and the retinal pigmented epithelium on the other. The inner epithelial layer is non-

29 pigmented. The ciliary muscles, which control the shape of the lens, extend from the

30 sclera and corneal limbal region towards the ciliary body and marginal zone. These 
Rasys et al.

Anterior eye development in brown anoles

1 muscles are in two groups, one distal and another proximal, represented by Crampton's

2 and Brücke's muscles, respectively. Like the iris, these muscles are striated.

In mammals, birds, and presumably reptiles, the ciliary body secretes aqueous

4 humor into the posterior chamber of the eye, which is the space between the iris and

5 lens. The aqueous humor then flows through the pupil to the anterior chamber, which is the space between the iris and cornea. In mammals and birds, the aqueous humor exits

7 the eye via outflow through a porous tissue called the trabecular meshwork, which is 8 located at the angle between the iris and cornea. ${ }^{25-27}$ In mammals, and perhaps birds, the aqueous humor flows from the trabecular meshwork into a vascular structure known as Schlemm's canal and then into the venous system. ${ }^{25-27}$ Inspection of the iridocorneal

11 angle in the eyes of adult $A$. sagrei, reveals a spongiform tissue comparable to the

12 trabecular meshwork in chickens. ${ }^{26}$ We were not able to identify a structure comparable

13 to Schlemm's canal as defined for the mammalian eye. ${ }^{25}$ Instead, we noted that the

14 vasculature from the choroid region extends between the ciliary body and the ciliary

15 muscles to the iridocorneal angle and propose that this contributes to the outflow of

16 aqueous humor.

\section{Lens development}

18 In anoles, the earliest stages of eye development take place while the eggs are in 19 the oviduct. While it is difficult to provide a precise timeline of development during this 20 period, based on our observations we estimate that the time between fertilization and 21 egg lay is close to 4 days. For comparative purposes, using morphological criteria we 22 have created a staging series that captures embryonic development that occurs in the 23 oviduct. Embryonic stages that occur pre-egg lay are denoted with the prefix "PL".

24 Stages observed in embryos post-egg lay use the Sanger staging series designations ${ }^{17}$ 25 and are denoted using the prefix "St". Stages PL 3-5 correspond to Sanger stages St 1-

26 3. For context, after egg lay it takes another $\sim 30$ days before the lizard hatches.

27 Embryos at about 1-day post fertilization (PL1), have optic vesicles but no clear

28 evidence of lens placodes. ${ }^{18}$ By PL2, the lens placode is evident in the surface

29 ectoderm overlying the neuroectoderm of the optic vesicle/early optic cup (Figure 3a).

30 By PL3, the lens placode has invaginated to form the lens pit (Figure 3b), which

31 develops into the lens vesicle by PL 4 (Figure 3c). At this time, the lens vesicle appears 
1 to be surrounded by a capsule (Figure 3c). At PL5 the lens is becoming polarized as

2 cells in the posterior vesicle elongate and differentiate to form primary lens fiber cells,

3 and cells in the anterior vesicle are differentiating to form the epithelium (Figure $3 \mathrm{~d}$ ). At

4 the time of egg lay ( St 4), the lens is completely separated from the surface ectoderm

5 and is composed of anterior cuboidal epithelial cells and posterior elongating fiber cells

6 (Figure 3e). The anterior cuboidal epithelial cells have formed a pseudostratified

7 epithelial layer, while the primary fiber cells have completely extended into the vesicle

8 space forming the nucleus of the lens (Figure 4.1,a).

After egg lay, the lens begins to increase in size with mitotic figures located in the

11 equator and well-defined anterior and posterior sutures are evident (Figure 4.2,b).

12 Within the anterior lens epithelium, which is approximately 2-4 cells thick (Figure 4.2,a),

13 mitotic cells are observed throughout the epithelial layer anterior to the lens equator

14 (Figure 5a). We did not observe any mitotic activity posterior to the lens bow, which

15 suggests that these cells are undergoing differentiation and likely express crystallins. By

16 stage 6, the anterior epithelial layer is thinner at its center and wider at its periphery

17 (Figure 4.3, 4.3a). Proliferating cells are present throughout the central and peripheral

18 lens epithelium as well as in the annular region. By St 9, when the anterior central

19 epithelium becomes a single cell layer (Figure 4.4,a), cell division appears to be limited

20 to the regions where the epithelium is still pseudostratified (Figure 5; diagramed in

21 Figure 2). By St 11, elongating fiber cells within the lens core are undergoing

22 denuclearization as pyknotic cells are evident within the lens nucleus (Figure 6.1,a); this

23 process appears to be mostly complete by St 14 (Figure 6.2-3). An organelle-free

24 zone (OFZ) is present in the lenses of St 15 embryos, which later expands in diameter

25 as the lens continues to grow (St 16-18, Hch; Figure 6.4-5). In adults, presumptive lens

26 fiber cells, identified by the presence of nuclei, are located throughout the center,

27 peripheral, and annular pad epithelial regions of the lens (Figure 1.1,b,c). Cells

28 undergoing denuclearization are also evident (Figure 1.b). These results suggest that

29 the lens continues to grow throughout the life of the animal. 
Rasys et al.

Anterior eye development in brown anoles

\section{Cornea development}

2 The surface ectoderm that will form the epithelial layer of the cornea is evident in embryos at PL 5 (Figure 3d). A few days later, at St 5, mesenchymal cells (presumptive

4 migrating neural crest cells) are found underlying the corneal epithelium near the edge 5 of the optic cup (Figure 7.1b). By St 6, the cornea has three distinct layers (Figure 7.2a). A thin acellular region, where Bowman's membrane will eventually develop, separates the epithelial and endothelial layers and marks the beginning of primary corneal stroma formation (Figure 7.2a). This acellular region, however, is not long lasting. It disappears shortly before stage 9 as the first signs of keratocytes are detected (Figure 7. 3a). A analogous acellular zone has also been described for the developing cornea in chicks $^{19,28,29}$, mice ${ }^{30}$ and primates ${ }^{21,31}$.

Stromal expansion occurs between St 10-14. The number of presumptive keratocytes in the stromal layer increases to 3-4 cells deep between St 10-11 (Figure 8.4a) followed by deposition of collagen fibers (St 12-14). By St 14, the cornea reaches its maximal cellularity and width (Figure 8.6a). The stroma begins to condense during St 15 , eventually shrinking nearly half its width by St 17 (Figure 9.8a, Figure 10). We postulate that the acellular layer immediately adjacent to the epithelium, is Bowman's membrane. We could not however, readily identify a Descemet's membrane. It is possible this layer is present but too thin to distinguish from the rest of the stroma in our histological sections. Accompanying these dynamic changes in stroma width are

21 flattening of all the cornea cell layers, particularly the endothelial cells (Figure 10). By

22 the time of hatching, the cornea is similar in all aspects of morphology and thickness to 23 the adult.

24 Iris development

In St 5 embryos, the developing iris is distinguishable from the neural retina as an anterior marginal tapering of the optic cup (Figure 7.1b). Iris development initiates on

27 the temporal side of the optic cup. By St 6, pigmentation can be seen accumulating

28 along the developing outer pigmented epithelial cell layer of the presumptive iris and 29 ciliary body. At this time, the outer pigmented epithelium is composed of a simple layer 30 of short columnar cells, while the inner epithelium is pseudostratified and columnar (Fig 31 7.2b). By St 7-9, the iris primordium is morphologically distinct from the ciliary body 
Rasys et al.

Anterior eye development in brown anoles

1 (Figure 7.2b-3b). During this time, inner epithelial cells of the iris are also accumulating

2 pigment, and by St 13-14, both iris outer and inner epithelial cell layers are heavily

3 pigmented (Figure 8.6b). As the embryo nears hatching, the iris outer and inner

4 epithelium becomes squamous-like in appearance (St 14-16) and by stage 17, greatly

5 resemblances that of the hatchling (Figure 8.6b, Figure 9.7-9b).

6 The iris stroma is evident in St 6 embryos as mesenchymal-like cells that are closely

7 associated with the iris outer pigmented epithelium (Figure 7.2b). By St 9 the cells

8 appear as a simple cuboidal cell layer (Figure 7.3b). Cells adjacent to the outer

9 pigmented epithelium are smaller and have round nuclei. Presumptive muscle fibers in

10 the iris stroma are evident by St 13, and exhibit mature characteristics by St 17-18

11 (Figure 9.8b).

\section{Ciliary body development}

13 The initial development of the ciliary body and iris occur concordantly. The ciliary

14 body proper is morphologically evident on the temporal side of the optic cup in St 5

15 embryos and on the nasal side by St 6 (Figure 7.2, 4.2d, Figure 11.1a, 2b). The start of

16 the ciliary body on the retina side is at the abrupt bend in the epithelium at the rim of the

17 optic cup and extends distally to the second convex flexure, which is adjacent to the

18 lens (Figure 7.2, 7.2c, 7.2d). The region distal to the second flexure is the iris. Shortly

19 after the bend in the epithelium appears at the distal edge of the optic cup, the cells of

20 the inner non-pigmented epithelium begin to organize into a simple cell layer,

21 delineating the neural retina from the ciliary body (Figure 7.1d-3d, Figure 11.3c-4b). By

22 St 16, the epithelium has become cuboidal in appearance (Figure 9.7d-8d).

23 Pigmentation of the presumptive ciliary body is first observed at St 4 in the temporal

24 region of the eye and later in the outer epithelial cells present in the sclera sulcus (St 5)

25 (Figure 7.1c,d). Unlike the iris, the inner epithelial layer of the ciliary body is mostly

26 devoid of pigmentation; however, cells near the iris-ciliary boundary have some pigment

27 granules.

28 Development of Iris and Ciliary body

29 The foremost observation we made while investigating the development of the iris

30 and ciliary body relates to their relative size and spatiotemporal patterning. We 
Rasys et al.

Anterior eye development in brown anoles

1 observed that the temporal areas were much longer than the nasal regions and that the

2 temporal side undergoes remodeling and differentiation prior to the nasal side (Figure

3 11). This patterning was evident shortly after anterior marginal tapering of the optic cup.

4 A prominent convex flexure, known in lizards as the sclera sulcus, forms along the

5 anterior margin and is first detected in the temporal region at stage 5 and later in the

6 nasal region by stage 6 (Figure 11.1a-2b). This trend continues to hold at later

7 timepoints when the iris and ciliary epithelium reorganize, forming the ciliary marginal

8 region and undergoing pigmentation (Figure 11.3c-4d). For the most part, the

9 development of nasal region appears to lag behind the temporal area by 1-2 stages

10 (Figure 11). We observed a similar spatiotemporal pattern in the developing anole

11 neural retina (Rasys et al., in preparation).

12 Embryonic Sclera Ossicles \& Ciliary muscle

13 Scleral ossicles are neural crest-derived membrane bones. The start of sclera

14 ossicle formation can be seen in embryos as early as St. 11 as a pale ring of papilla in

15 the conjunctiva surrounding the cornea and iris (Figure 11.5-6; see also, Anolis sagrei

16 eye development poster in Supplementary Data by Rasys et al. ${ }^{18}$ ). In cross-section,

17 condensing mesenchymal cells can be visualized and are located just posterior to the

18 cornea-conjunctiva epithelium (Figure 8.4c). Between St 12-13, these cells organize into

19 flat sheets approximately a few cells thick, extending initially from the sclera proper to

20 the iridocorneal angle in an overlapping radial pattern (Figure 8.5c, 6c). By stages 14-

21 15, the sclera ossicle anlagen begins to take on a cartilaginous-like appearance (Figure

22 8.6c, Figure 9.7-8c,d) and by stage 17, lacuna can be observed around cell nuclei in

23 histological sections. Prior to this event, sclera extension in the temporal region takes

24 place (St 10-14) and by stages 16-17, temporal asymmetry is easily seen. ${ }^{18}$ As the

25 embryo continues to develop prior to hatching, the sclera ossicles thicken and expand

26 from the sclera proper to the corneal boundary (Figure 9.8-9c,d).

27 In concert with sclera ossicle development, mesenchymal cells that give rise to the

28 presumptive ciliary muscles are located adjacent to the developing ossicle (Figure 7.3c,

29 Figure 8.4-5c,d). At stage 12 these cells occupy a broad region extending the entire

30 length of the sclera sulcus. Ciliary muscle differentiation becomes evident between

31 stages 13-14 as a condensation of the mesenchyme. Muscle fibers are present by 
Rasys et al.

Anterior eye development in brown anoles

1 stage 15. By stage 17, ciliary muscle resembles that of the hatchling (Figure 9.7-9c,d).

2 Zonular fibers are detected at the time of hatching.

Development of the Trabecular Meshwork

The iridocorneal angle is clearly evident in embryos at St. 9 as a separation of the iris stroma from the cornea, forming the anterior chamber (Figure 7.3, Fig 11.4). By St 11 , a knot of mesenchymal cells separates the anterior chamber from a loose arrangement of cells sandwiched between the ciliary body and limbus (Figure 8.4c). We

8 are defining this loose arrangement of cells as the trabecular meshwork in lizards, which 9 bears resemblance to that of the early chick. ${ }^{26}$ By stage 16-17, the trabecular 10 meshwork appears to be largely consolidated near the iris-ciliary boundary and 11 resembles that of the adult (Figure 9.7-8c). Bordering the ciliary muscle and adjacent to

12 the trabecular meshwork are pigmented vascular endothelial cells that extend from the 13 iridocorneal angle into the choroidal layer (Figure 8.6c,d, Figure 9.7-9c-d), which may 14 serve to drain the aqueous humor.

\section{Discussion}

Here, for the first-time, we describe in detail anterior eye development in a reptile,

17 Anolis sagrei. We began our study by performing a detailed histological analysis of the

18 structures of the adult eye. Conceptually, this starting point permits structural

19 comparisons of the anterior segment in the brown anole with other species. A catalog of

20 morphological similarities and differences between anole species and, more broadly,

21 other reptiles can be used to index how representative the brown anole is as a reptile

22 model for eye development. Pragmatically, this foundational work is required to support

23 the study of anterior eye development in reptiles. Although there are a number of

24 published reports on the reptilian eye, most are in the older literature and deal primarily

25 with external anatomy and/or the structure of the adult retina. ${ }^{1,9}$ As a consequence,

26 there is a paucity of detailed comparative information about the anterior eye in reptiles

27 and its development. The data that does exist is mostly in the form of summary

28 sketches that capture nicely the key morphological features of the anterior eye but lack

29 the cellular detail useful for contemporary developmental studies. 
Rasys et al.

Anterior eye development in brown anoles

Comparative assessments can be made at the gross anatomical level. A. sagrei possesses features found in lizards and turtles, but not snakes, amphibians or placental mammals. ${ }^{1,9}$ These include the presence of scleral bone and cartilage, a lens with an annular pad, and skeletal rather than smooth muscles in the iris and ciliary body. These unique features are also found in birds. ${ }^{1}$ Compared with other anoles, we find that the anterior segment of $A$. sagrei is structurally similar to that in $A$. carolinensis (data not shown) and $A$. lineatopus ${ }^{9}$.

The most striking difference in the anterior segment of anoles compared to most other reptiles, birds and mammals is the structure of the adult cornea. In A. sagrei, the corneal epithelium is largely composed of a single basal cell sheet (Figure 1.1a). This was surprising as the corneal epithelium in many vertebrates is a stratified squamous epithelium consisting of several layers of cells. For example, the adult epithelium in chickens is typically composed of 6-7 cell layers, ${ }^{19}$ while mice have $4-5$ cell layers, ${ }^{20}$ and humans have 5-7 layers. ${ }^{21,32}$ Among the reptiles that have been examined, the number of cell layers varies depending on the species. For example, the cornea epithelium is 23 cells thick in grass snakes (Natrix natrix) and sand lizards (Lacerta agilis), and 3-4 cell layers thick in pond tortoises (Emys orbicularis). ${ }^{1,22}$ The anole corneal stroma is also thinner relative to that in other reptiles, birds, and placental mammals. ${ }^{19-21,28,30-37}$

The physiological impact of a thin cornea, and especially the epithelial layer, is

21 element in establishing the overall optical properties of the eye. In addition to its barrier

22 function, the epithelial layer plays a critical role in maintaining the clarity of the cornea.

23 The epithelial layer is constantly turning over. In mammals, a population of stem cells,

24 located at corneal-scleral junction, give rise to the corneal epithelial cells that maintain

25 the ocular surface. Newly born epithelial cells migrate radially into the basal cell layer of 26 the epithelium. As cells desquamate from the corneal surface, cells from deeper layers 27 migrate towards the surface. As cells migrate to more superficial layers, they also 28 undergo changes in their morphology and physiological properties. In birds and 29 mammals, basal cells that leave the basement membrane normally take on a polyhedral 30 shape and begin expressing keratins. These cells then take on a squamous 
1 morphology, with flattened nuclei, as they move towards the corneal surface. It will be

2 interesting to determine the mechanisms that maintain the ocular surface in anoles.

The development of the anterior segment in $A$. sagrei progresses in a similar fashion

4 to that observed for all vertebrates. The first structure to form is the lens, followed by the

5 cornea and later the iris, ciliary body, and structures responsible for draining the aqueous humor from the eye. ${ }^{20,30,37-42}$. However, the ways in which the structures of the

7 anterior segment develop are more similar to the chicken ${ }^{19,28,33-36}$ than mice ${ }^{20,30}$ or

8 haplorhini primates. ${ }^{21,31,37}$. This correlation is consistent with the phylogenetic

9 relationship of reptiles to birds and mammals.

Based on our histological analysis it is unclear if lizards possess Schlemm's canal. In his landmark comparative work on the vertebrate eye, Walls (1942) stated that

13 mammals. In humans and other primates, Schlemm's canal is an endothelium-lined

14 vascular structure immediately adjacent to the juxtacanalicular region of the trabecular

15 meshwork and encircles the cornea. ${ }^{25,42}$ The endothelial cells that make up the inner

16 and outer walls of Schlemm's canal have distinctive characteristics that can be seen in

17 histological sections. Using these characteristics as a guide, we have not been able to

18 identify a comparable structure in either the adult or developing eye of $A$. sagrei. Our

19 failure to identify Schlemm's canal in the brown anole is consistent with the observations

20 reported for $A$. lineatopus by Underwood (1970), in which he noted that Schlemm's

21 canal "is poorly defined in Anolis."

22 The primary functions of Schlemm's canal are to maintain intraocular pressure and

23 serve as a conduit for the aqueous humor to flow into the venous system. ${ }^{25,42} \mathrm{We}$

24 propose that this function is served in anoles by the vasculature from the choroid region

25 that extends between the ciliary body and the ciliary muscles to the iridocorneal angle.

26 Elucidating the cellular, molecular, and genetic mechanisms that regulate the

27 development of the aqueous humor outflow pathways in anolis lizards may provide

28 insights into the different ways this important fluid handling problem can solved in

29 nature. 


\section{References}

2 1. Walls GL. The Vertebrate Eye and Its Adaptive Radiation. Bloomfield Hills, Michigan: The Cranbrook Institute of Science; 1942.

$4 \quad$ 2. Ramón y Cajal S. La rétine des verébrés. 18921982.

5 3. Slonaker JR. A comparative study of the area of acute vision in vertebrates. Boston:

4. Darwin C. On the origin of species by means of natural selection, or, The preservation

9 5. Miesfeld JB, Brown NL. Eye organogenesis: A hierarchical view of ocular development. Curr Top Dev Biol. 2019;132:351-393. https://doi.org10.1016/bs.ctdb.2018.12.008.

6. Chow RL, Lang RA. Early eye development in vertebrates. Annu Rev Cell Dev Biol.

14 7. Fuhrmann S. Eye morphogenesis and patterning of the optic vesicle. Curr Top Dev Biol. 2010;93:61-84. https://doi.org10.1016/b978-0-12-385044-7.00003-5.

8. Saha MS, Servetnick M, Grainger RM. Vertebrate eye development. Curr Opin Genet Dev. 1992;2(4):582-8.

Underwood G. The Eye. In: Gans C, Parsons TS, eds. Biology of the Reptilia, Volume 2. Morphology B. Vol 2. Academic Press; 1970:1-93. Zootaxa. Jan 24 2018;4375(2):257-264. https://doi.org10.11646/zootaxa.4375.2.5.

12. Infante CR, Rasys AM, Menke DB. Appendages and gene regulatory networks: Lessons from the limbless. Genesis. Jan 2018;56(1). https://doi.org10.1002/dvg.23078. Integrative Model of Anatomical Evolution. Methods Mol Biol. 2017;1650:285-297. https://doi.org10.1007/978-1-4939-7216-6 19. Rasys AM, Park S, Ball RE, Alcala AJ, Lauderdale JD, Menke DB. CRISPR-Cas9 Gene Editing in Lizards through Microinjection of Unfertilized Oocytes. Cell Reports. Aug 27 2019;28(9):2288-+. https://doi.org10.1016/j.celrep.2019.07.089. 
Rasys et al.

Anterior eye development in brown anoles

1 14. SANGER TJ, HIME PM, JOHNSON MA, DIANI J, LOSOS JB. Laboratory protocols for

2 husbandry and embryo collection of Anolis lizards. Herpetological Review.

$32008 ; 39(1): 58-63$.

4 15. Conroy CJ, Papenfuss T, Parker J, Hahn NE. Use of tricaine methanesulfonate (MS222) for euthanasia of reptiles. Journal of the American Association for Laboratory Animal Science : JAALAS. 2009;48(1):28-32.

16. Association AVM. AVMA Guidelines for the Euthanasia of Animals: 2020 Edition. 2020.

19. Meyer D, O’Rahilly R. The development of the cornea in the chick. 1959;7(3):303315.

20. Smith RS, John SWM, Nishina PM, Sundberg JP. Systematic Evaluation of the Mouse

21. Sevel D, Isaacs R. A re-evaluation of corneal development. Trans Am Ophthalmol Soc.

23. Willekens B, Vrensen G. Lens fiber organization in four avian species: a scanning electron microscopic study. Tissue Cell. 1985;17(3):359-77. https://doi.org10.1016/0040-8166(85)90055-2.

24. Persons BJ, Modak SP. The pattern of DNA synthesis in the lens epithelium and the annular pad during development and growth of the chick lens. Exp Eye Res. 1970;9(1):144-51. 
Rasys et al.

Anterior eye development in brown anoles

1 25. Tamm ER. The trabecular meshwork outflow pathways: structural and functional aspects. Exp Eye Res. Apr 2009;88(4):648-55. https://doi.org10.1016/j.exer.2009.02.007.

4 26. Trejo-Reveles V, McTeir L, Summers K, Rainger J. An analysis of anterior segment

27. Pizzirani S, Gong H. Functional Anatomy of the Outflow Facilities. Vet Clin North Am

28. Trelstad RL, Coulombre AJ. Morphogenesis of the collagenous stroma in the chick cornea. The Journal of Cell Biology. Sep 1971;50(3):840-858. https://doi.org10.1083/icb.50.3.840.

29. Hay ED. Development of the Vertebrate Cornea. In: Bourne GH, Danielli JF, Jeon KW,

30. Pei YF, Rhodin JA. The prenatal development of the mouse eye. Anat Rec. Sep

31. Rones B. Development of the Human Cornea. Archives of Ophthalmology. Oct 01 1932;8(4):568-575.

32. Zieske JD. Corneal development associated with eyelid opening. Int J Dev Biol. 2004;48(8-9):903-11.

35. Ikeda A, Maisel H, Waggoner D. An immunofluorescent study of cornea development

36. Coulombre AJ, Coulombre JL. Corneal development. I. Corneal transparency.J Cell Physiol. Feb 1958;51(1):1-11.

37. Mann IC. The development of the human eye. The University Press; 1928. 
Rasys et al.

Anterior eye development in brown anoles

1 38. Barishak YR. Embryology of the Eye and Its Adnexa. Karger; 2001.

2 39. O'Rahilly R, Meyer DB. The early development of the eye in the chick. Cells Tissues

3 Organs. 1959;36(1-2):20-58.

4 40. O'Rahilly R. The prenatal development of the human eye. Exp Eye Res. Aug 1975;21(2):93-112. https://doi.org10.1016/0014-4835(75)90075-5.

6 41. Barber AN. Embryology of the human eye. 1955.

7 42. Dautriche CN, Tian Y, Xie Y, Sharfstein ST. A closer look at Schlemm's canal cell

8 physiology: implications for biomimetics. Journal of functional biomaterials.

9 2015;6(3):963-985. 


\section{Figure Legends}

Figure 1. Anterior structures of the adult anole eye. (1) is a horizontal section showing lens, cornea, iris, and ciliary body. (a-d) are high magnification views of cornea (1.a), lens bow (1.b), lens epithelial (1.c), and limbus region (1.d). (1.a-d) markers represent; Con - conjunctiva, ScP - sclera proper, LSu - lens suture, AnP - annular pad, LCa -lens capsule, SO - sclera ossicles, arrowheads - corneal epithelial, bar - stroma, arrow - corneal endothelial layer, notches - bowman's membrane boarder, and narrow arrow heads - lens epithelial cells. (2) is a horizontal section depicting iris, ciliary body, and ciliary marginal zone; lines indicate ciliary marginal zone (solid) and iris (dashed) boundaries. (2.a-c) are high magnified inserts of the ciliary marginal zone (2.a), ciliary body (2.b), and iris (2.c). Markers; SO - sclera ossicles, Zon - zonular fibers, CMZ - ciliary marginal zone, PE - pigment epithelium, nPE - nonpigmented epithelium, CM - ciliary muscle, IrSm - iris smooth muscle, IrPE - iris pigmented epithelium, and Irid -

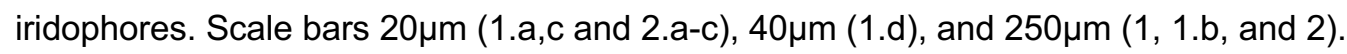

Figure 2. Anatomical diagram of the anole lens. $1^{\circ} \mathrm{LF}$ - primary lens fiber, $2^{\circ} \mathrm{LF}-$ secondary lens fiber.

Figure 3. Early anole embryonic eye development. (a-e) are coronal sections from PL2 - Stage 4 embryos depicting lens placode, optic cup (a), lens pit (b), and lens vesicle formation (c-d); Scale bars $50 \mu \mathrm{m}(\mathrm{a}-\mathrm{e})$, insert (a) $20 \mu \mathrm{m}$.

Figure 4. Lens maturation in the developing embryonic anole eye. (1-5) represent coronal (1) and horizontal (2-5) sections from the center lens from embryonic stages 4, 5, 6, 9, and hatchling; scale bars $100 \mu \mathrm{m}$. High magnification views of lens epithelium (dashed boxes, 1.a-5.a) and lens bow (solid

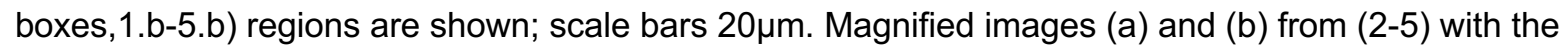
exception of (5.b) are to scale with one another, respectively. Markers; LE - lens epithelium, LSu - lens suture, $1^{\circ} \mathrm{LF}$ - primary lens fiber, $2^{\circ} \mathrm{LF}$ - secondary lens fiber, LB - lens bow, LCa - lens capsule, and * indicates sectioning artifact.

Figure 5. Cell proliferation in the anole lens epithelium. (a-f) shows horizontal sections from stages 5, 6, 7, 9, 11, and 13 embryos; scale bar $100 \mu \mathrm{m}$. High magnification inserts show miotic figures (arrow heads); scale bar $20 \mu \mathrm{m}$. Sections (a-f) and high magnification inserts are to scale with one another, respectively.

Figure 6. Denuclearization of the lens center. (1-5) depict horizontal sections of the lens nucleus; scale bar $100 \mu \mathrm{m}$. High magnification inserts show pyknotic figures (notches) in the lens center (OFZ organelle free zone); scale bar $20 \mu \mathrm{m}$. Sections (1-4) and high magnification inserts (a-d) are to scale with

37 one another, respectively.

\section{Page 19 of 21}


Figure 7. Early embryonic development of the anterior segment of the anole eye. (1-3) depict horizontal sections of the center eye from embryonic stages 5, 6, and 9; scale bars $100 \mu \mathrm{m}$. High magnification inserts show cornea (a), iris (b), sclera sulcus (c), and ciliary body (d) regions of the developing eye; scale bars $20 \mu \mathrm{m}(\mathrm{a}-\mathrm{d})$. Magnified inserts (1-3) are to scale with one another, respectively. Markers represent; CE - cornea epithelium, PE - pigment epithelium, nPE - nonpigmented epithelium, RBC - nucleated red blood cell, IrPE - iris pigmented epithelium, CMZ - ciliary marginal zone, arrowheads - cornea epithelium, * or bar - cornea stroma (2.a-3.a), arrow - cornea endothelium, * - iridocorneal angle (3.b), narrow notches - iris stroma anlagen.

Figure 8. Mid embryonic development of the anterior segment of the anole eye. (4-6) depict horizontal sections of the center eye from embryonic stages 11, 12, and 14; scale bars $100 \mu \mathrm{m}$. High magnification inserts show cornea (a), iris (b), sclera sulcus (c), and ciliary body (d) regions of the developing eye; scale bars $20 \mu \mathrm{m}$. Magnified inserts (4-6) are to scale with one another, respectively. Markers; CE - cornea epithelium, PE - pigment epithelium, IrPE - iris pigment epithelium, nPE - nonpigmented epithelium, TM - trabecular meshwork, RBC - nucleated red blood cell, CMZ - ciliary marginal zone, SO - sclera ossicles, CBM - ciliary body muscle, arrowheads - cornea epithelium, bar - cornea stroma, arrow cornea endothelium, * - iridocorneal angle (4.b-5.b), and narrow notches - iris or ciliary stroma anlagen.

Figure 9. Late embryonic development of the anterior segment of the anole eye. (7-9) depict horizontal sections of the center eye from embryonic stages 15,17 , and hatchling; scale bars $100 \mu \mathrm{m}$. High magnification inserts show cornea (a), iris (b), sclera sulcus (c), and ciliary body (d) regions of the

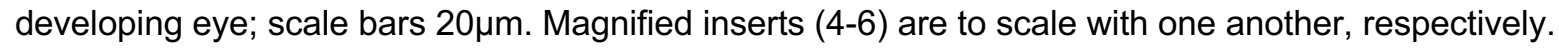
Markers; CE - cornea epithelium, IrPE - iris pigment epithelium, nPE - nonpigmented epithelium, TM trabecular meshwork, RBC - nucleated red blood cell, CBM - ciliary body muscle, SO - sclera ossicles, $\mathrm{CMZ}$ - ciliary marginal zone, RPE - retinal pigmented epithelium, arrowheads - cornea epithelium, bar cornea stroma, arrow - cornea endothelium, narrow notches - iris or ciliary stroma anlagen, and * sectioning artifacts.

Figure 10. Corneal transparency increases as stroma condenses. Top panel (a-e) shows horizontal sections of the cornea center; scale bar $20 \mu \mathrm{m}$. Bottom panel $(\mathrm{f}-\mathrm{j})$ depicts the dorsal view from the same eyes shown in the panel above; scale bars $250 \mu \mathrm{m}$. Sections (a-e) and dorsal view images (f-i) are to scale with one another, respectively. Markers; arrowheads -2 corneal epithelial cells on top of each other and notches - coalescent of bowman's membrane boarder.

Figure 11. Spatiotemporal patterning of the anterior segment. (1-7) shows a lateral view of the left eye from embryonic stages $5,6,8,9,11$, and 16 as well as the hatchling; scale bars $100 \mu \mathrm{m}$. (a-g) depicts

\section{Page $\mathbf{2 0}$ of $\mathbf{2 1}$}


bioRxiv preprint doi: https://doi.org/10.1101/2021.02 15.429783; this version posted February 16, 2021. The copyright holder for this preprint (which was not certified by peer review) is the author/funder, who has granted bioRxiv a license to display the preprint in perpetuity. It is made available under aCC-BY-NC 4.0 International license.

\section{Rasys et al.}

Anterior eye development in brown anoles

1 another. Markers; ScIS - sclera sulcus, AC - anterior chamber, arrows - iris flexure, arrow heads - ciliary

2 margin zone, notches (white) - conjunctive papilla or sclera ossicles, and open arrows (white) - dorsal 3 and ventral iris notches. 
Fiqure 1 bioRxiv preprint doi: https://doi.org/10.1101/2021.02.15.429783; this version posted February 16, 2021. The copyright holder for this preprint (which was not certified by peer review) is the author/funder, who has granted bioRxiv a license to display the preprint in perpetuity. It is made available under aCC-BY-NC 4.0 International license.
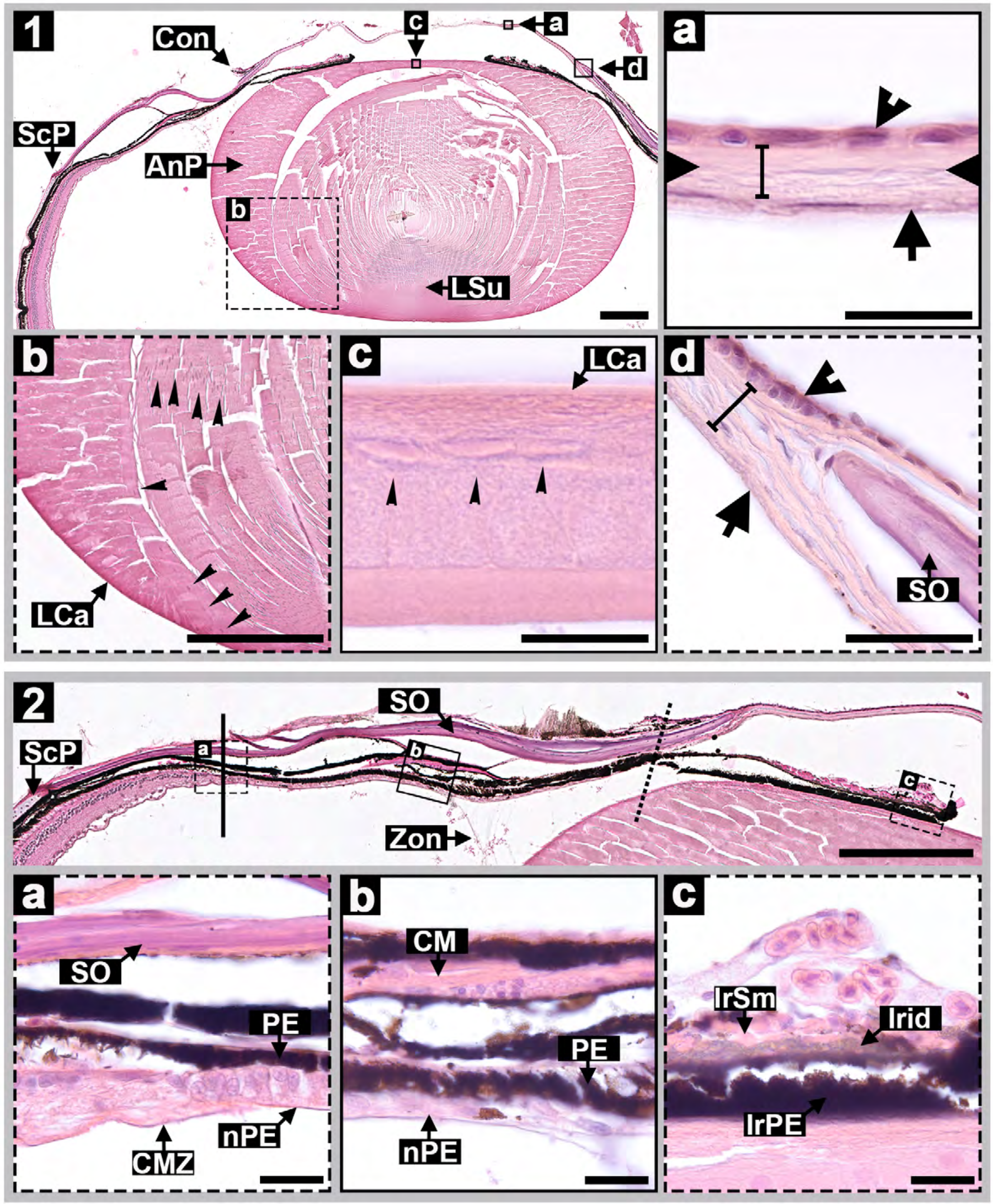
Fiqure 2 bioRxiv preprint doi: https://doi.org/10.1101/2021.02.15.429783; this version posted February 16, 2021. The copyright holder for this preprint (which was not certified by peer review) is the author/funder, who has granted bioRxiv a license to display the preprint in perpetuity. It is made available under aCC-BY-NC 4.0 International license.

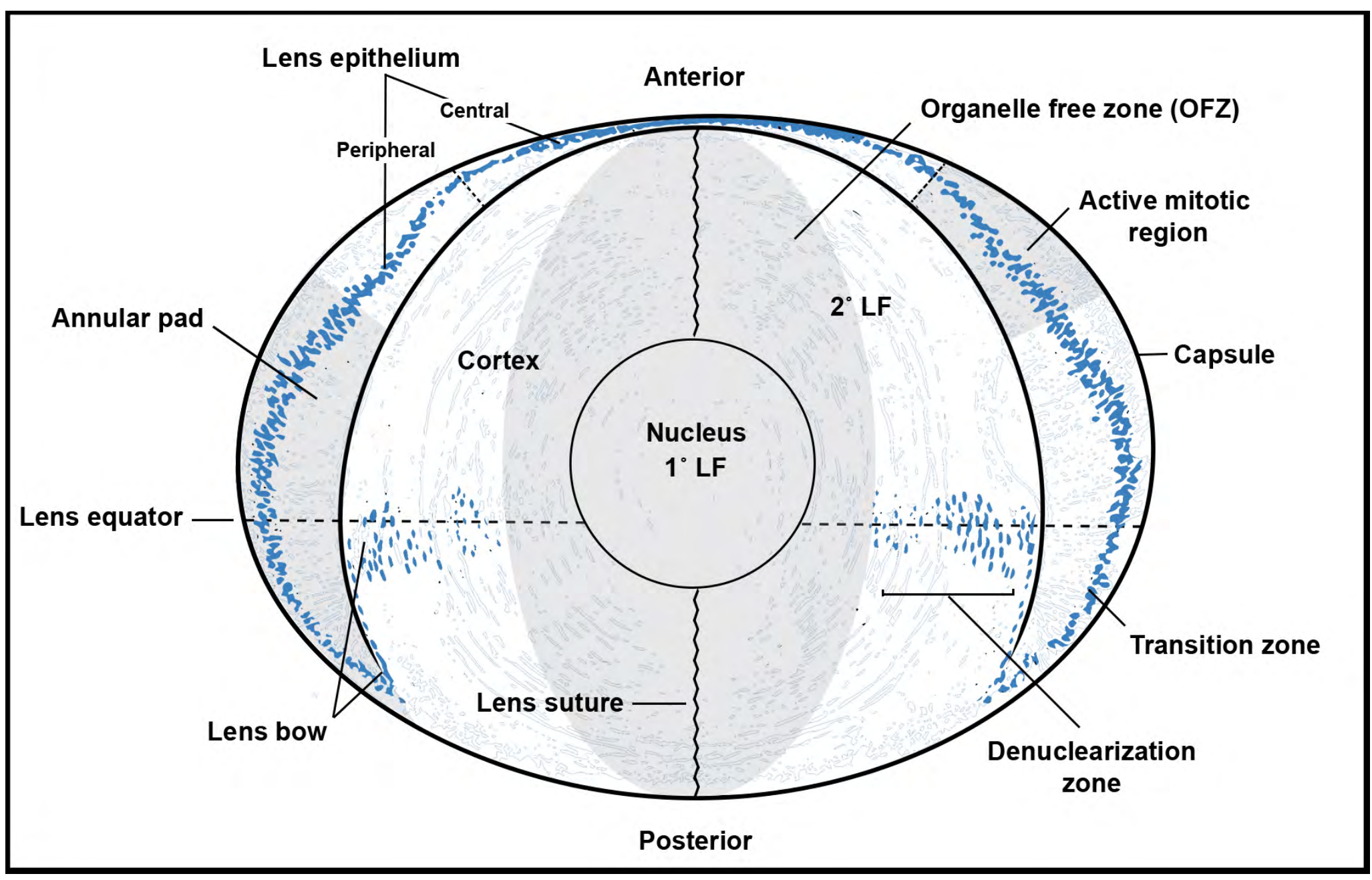



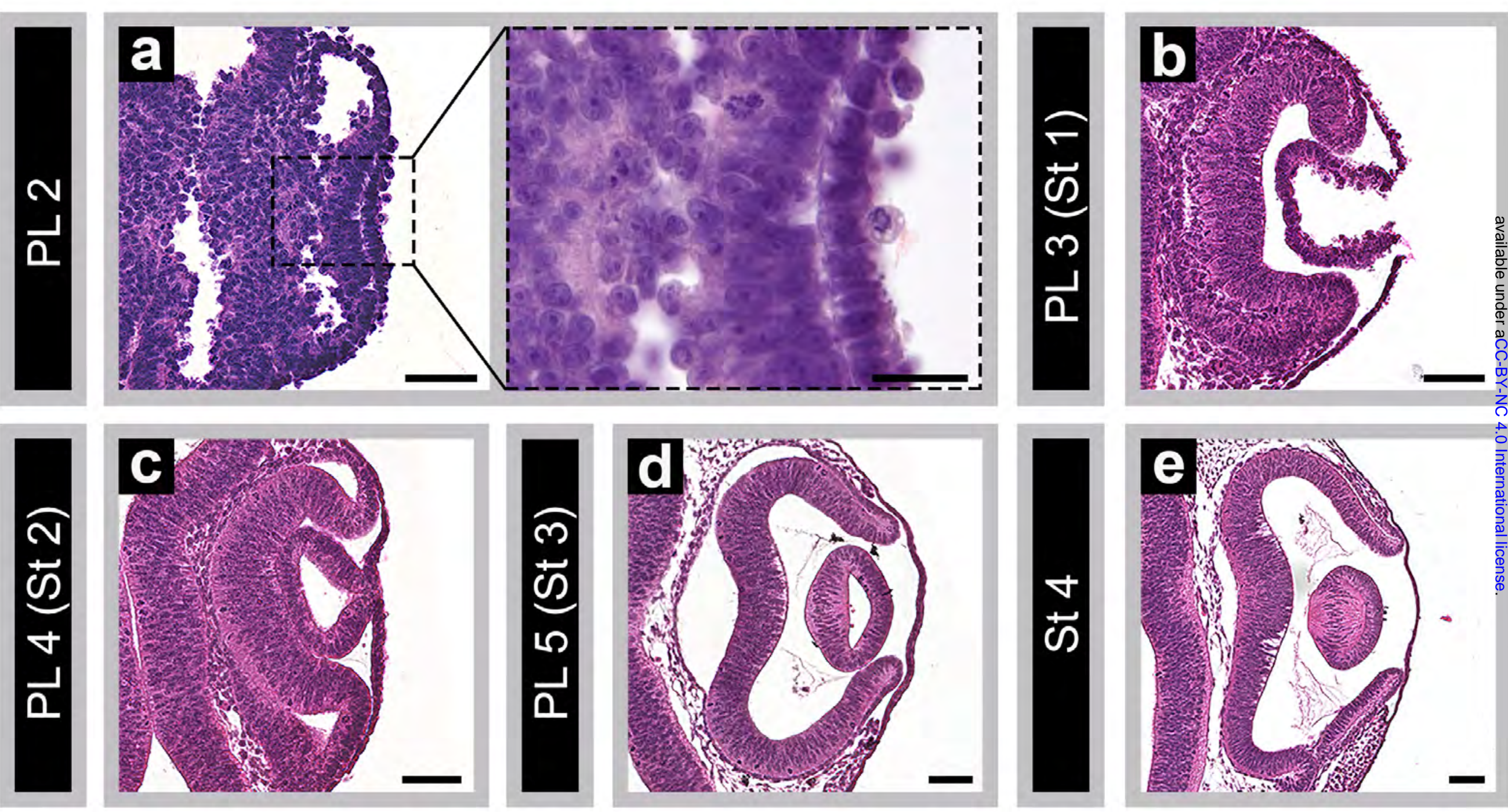
Fiqure 4 bioRxiv preprint doi: https://doi.org/10.1101/2021.02.15.429783; this version posted February 16, 2021. The copyright holder for this preprint (which was not certified by peer review) is the author/funder, who has granted bioRxiv a license to display the preprint in perpetuity. It is made
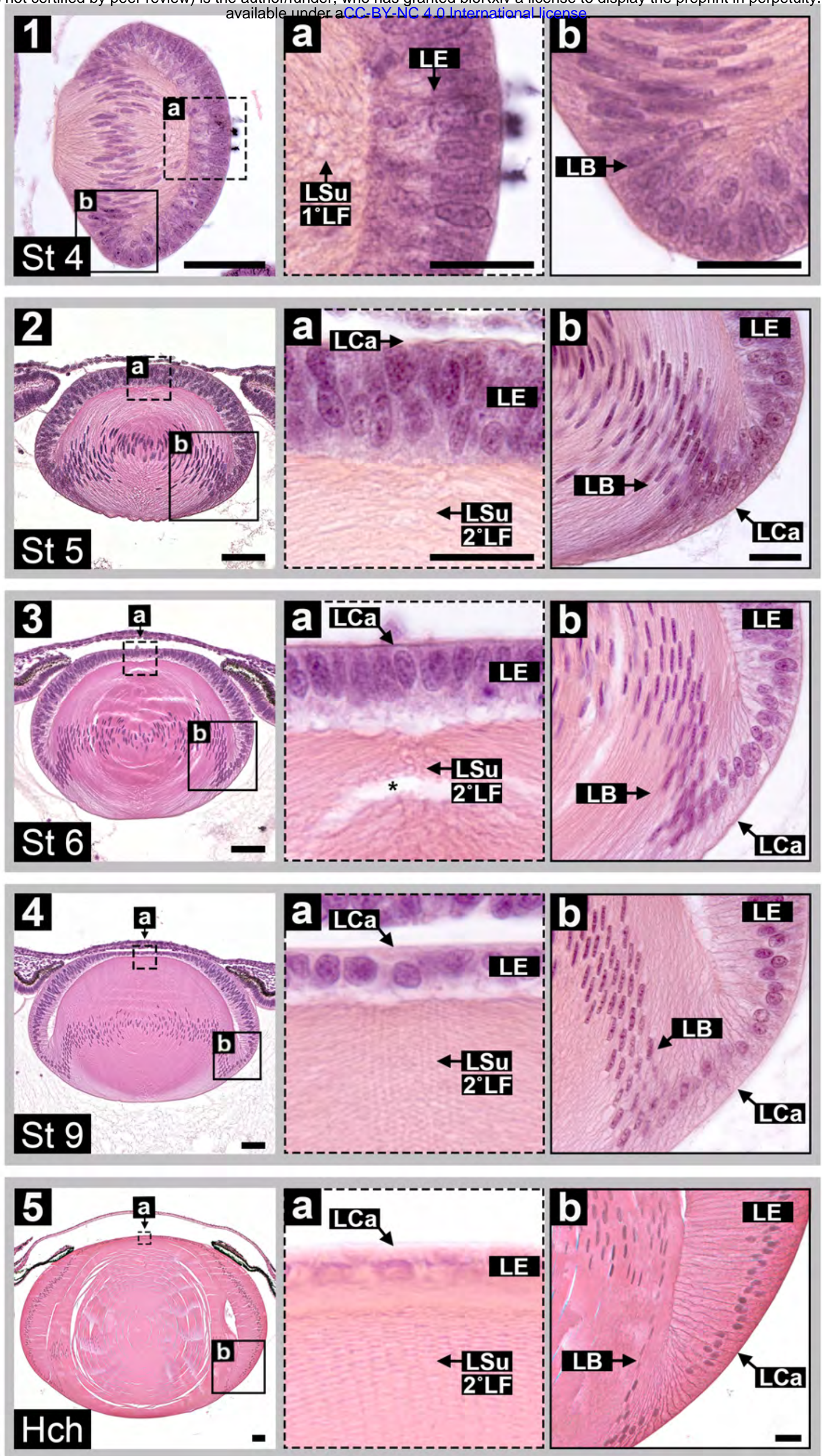


\section{Figure 5}
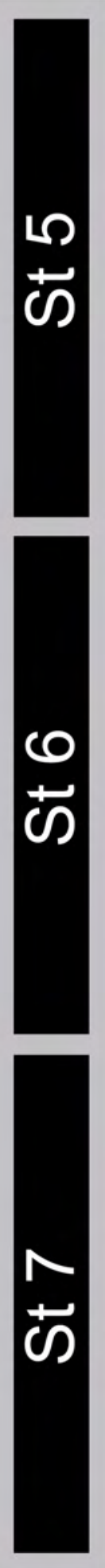

ס
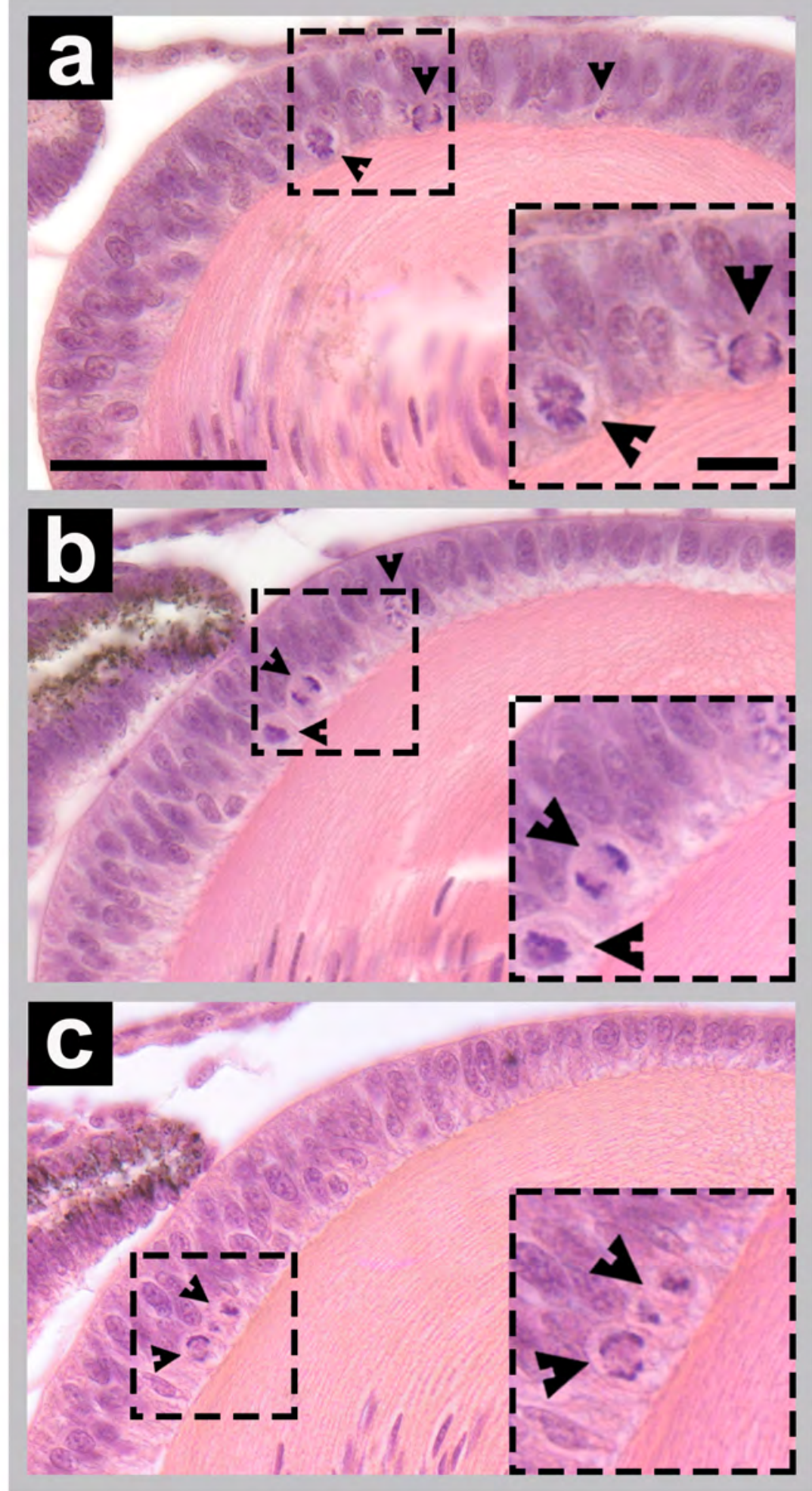
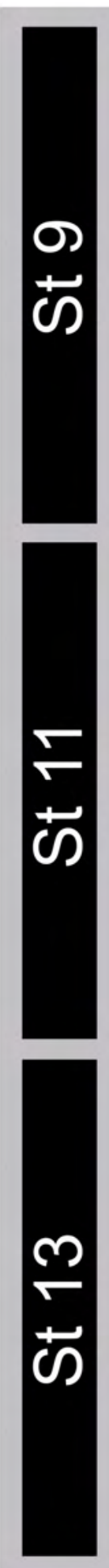

\section{d}

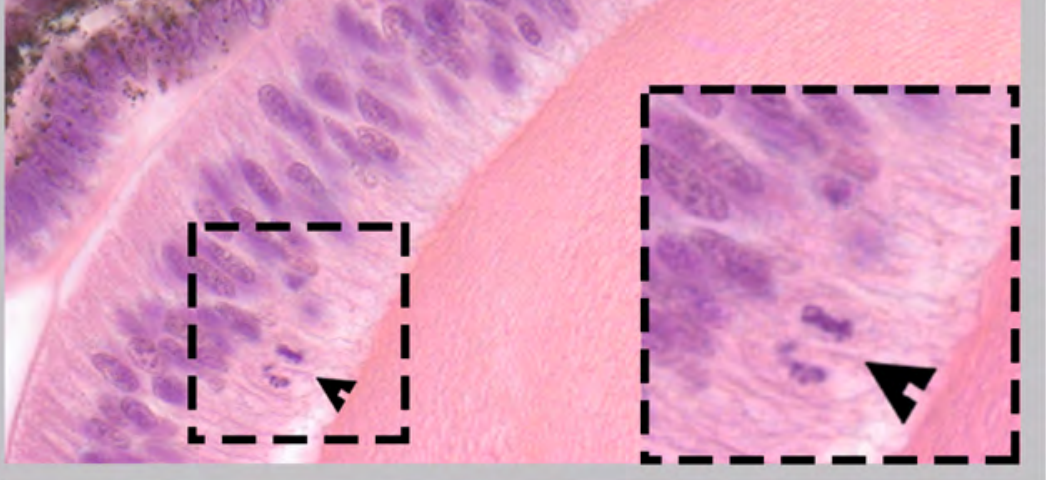

\section{e}
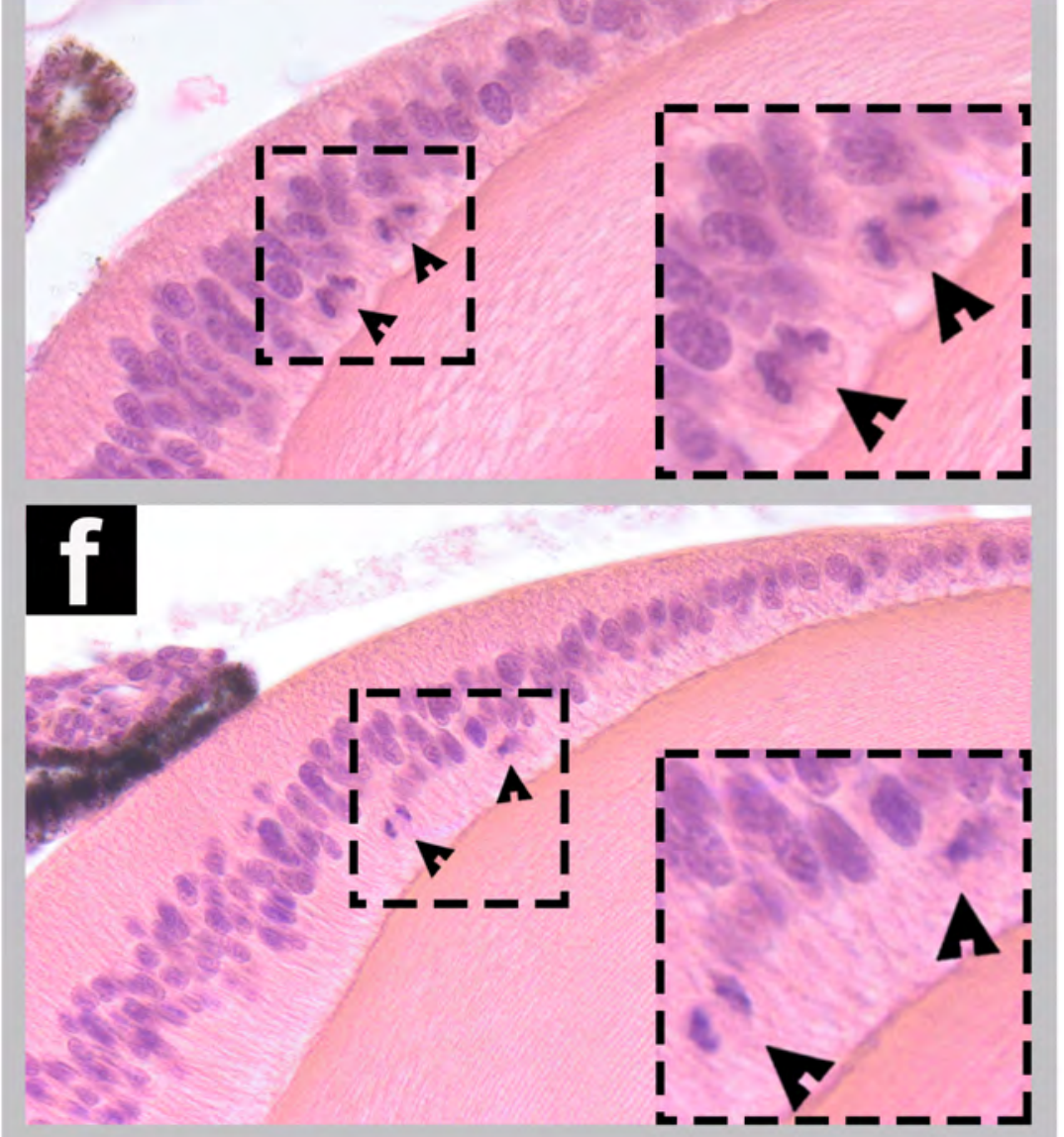

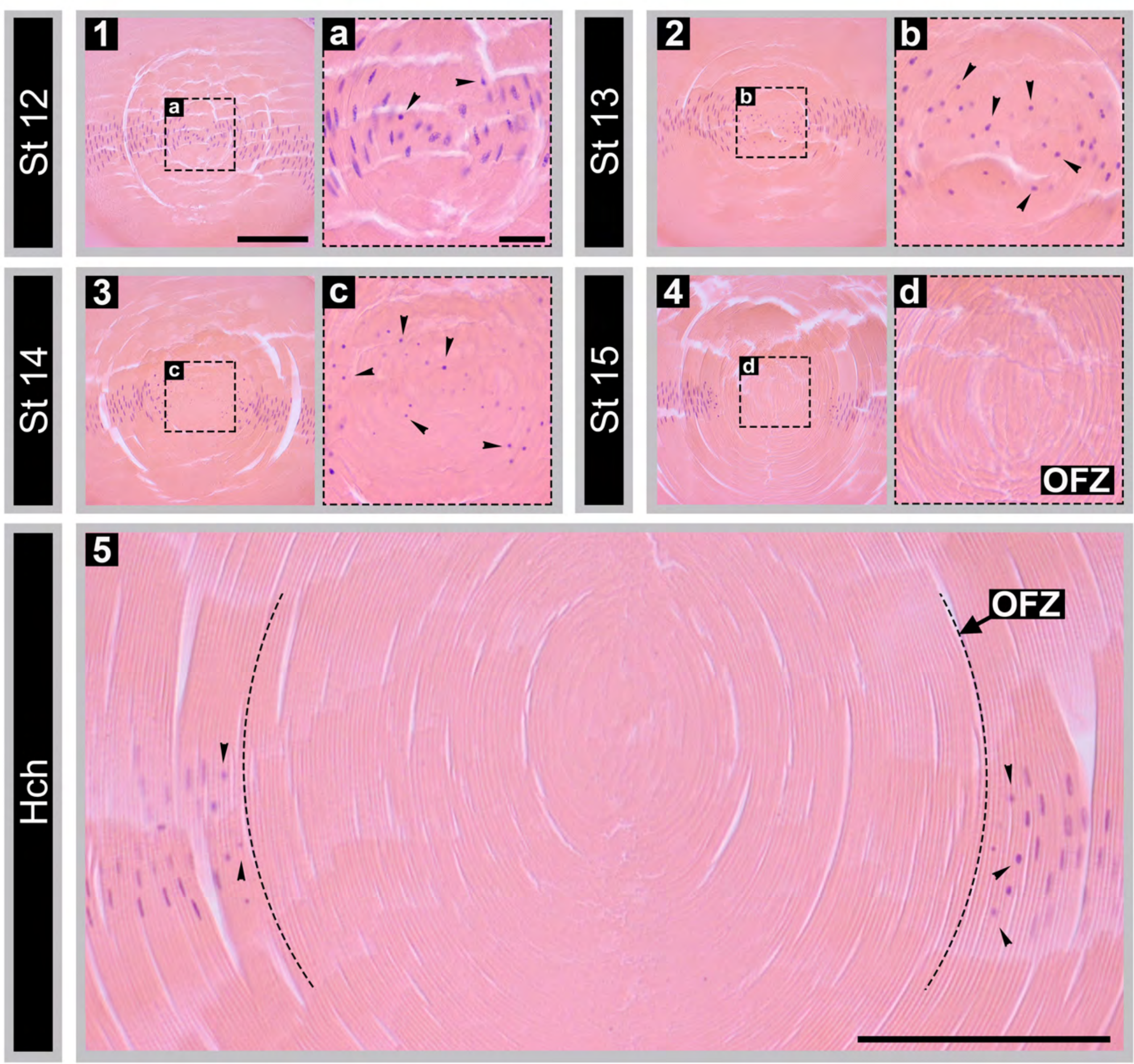

5

돈

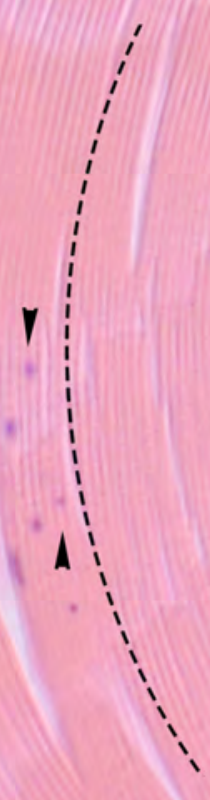

OFz

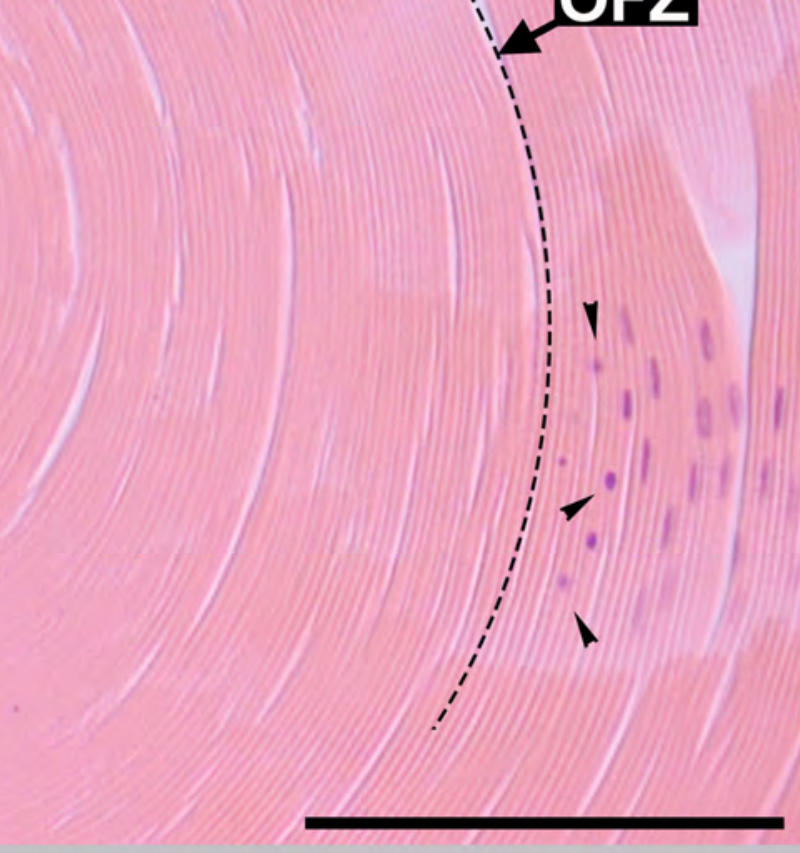


Figure 7 bioRxiv preprint doi: https://doi.org/10.1101/2021.02.15.429783; this version posted February 16, 2021. The copyright holder for this preprint (which was not certified by peer review) is the author/funder, who has granted bioRxiv a license to display the preprint in perpetuity. It is made
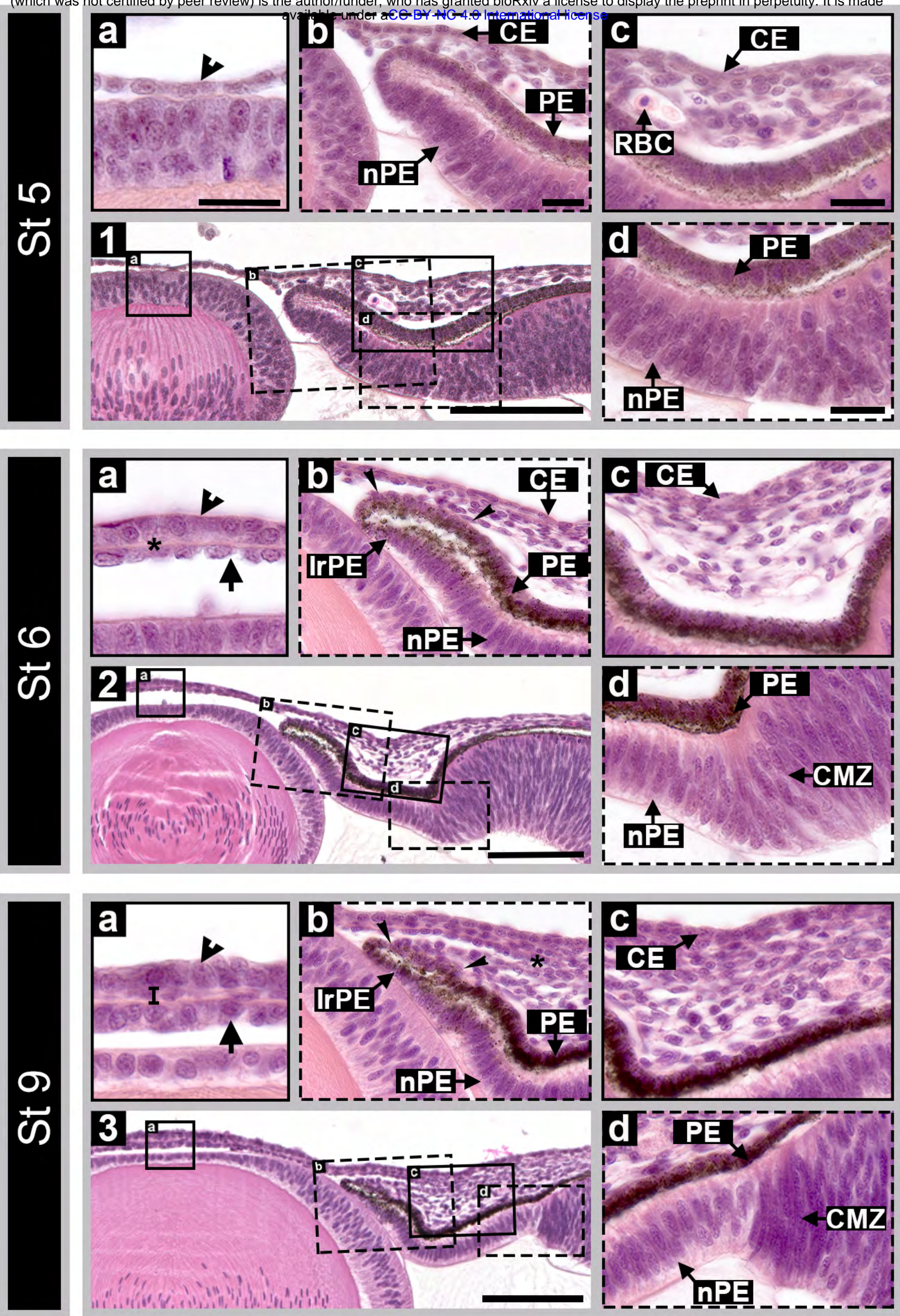
Figure 8 bioRxiv preprint doi: https://doi.org/10.1101/2021.02.15.429783; this version posted February 16, 2021. The copyright holder for this preprint
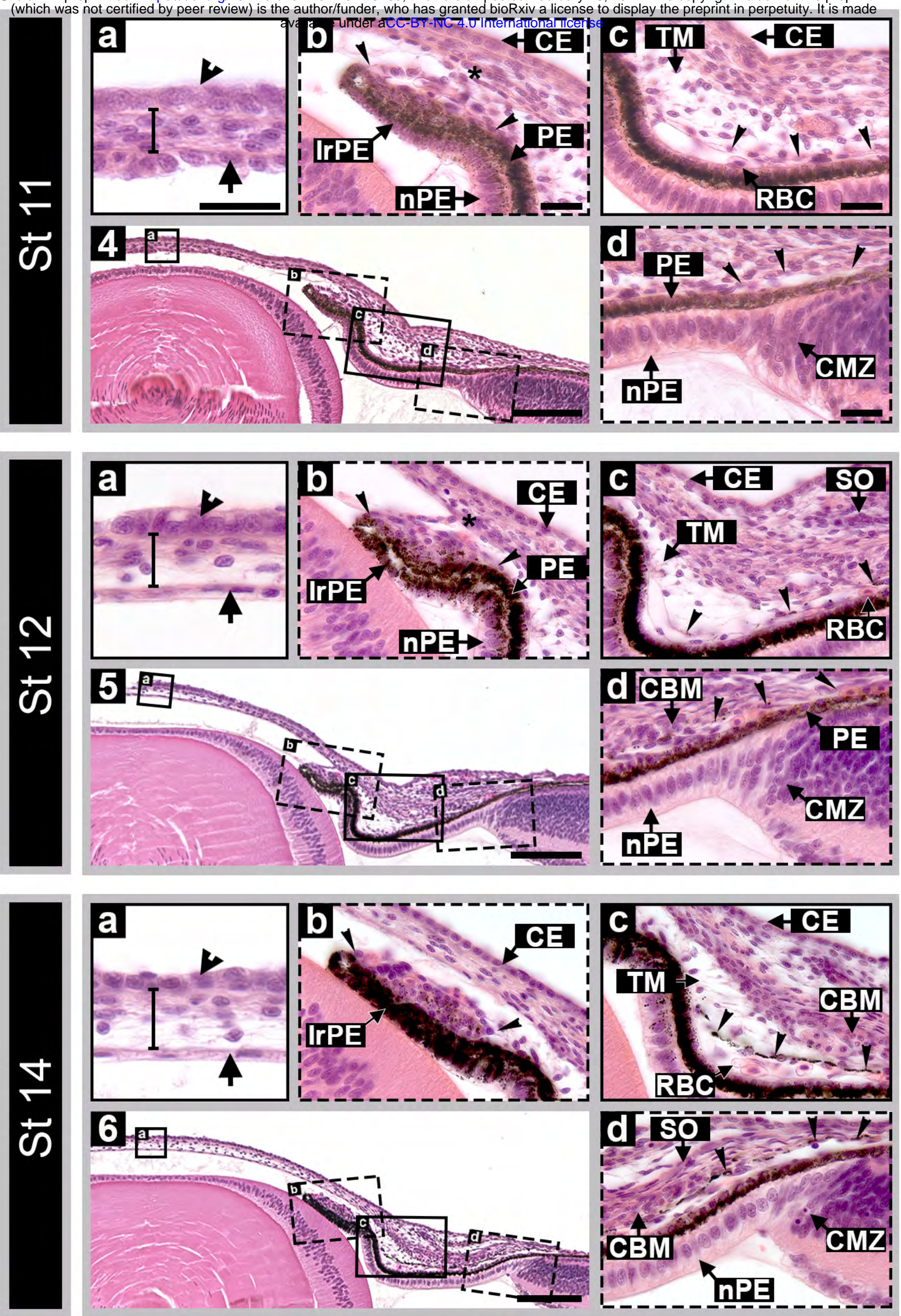
Figure 9 bioRxiv preprint doi: https://doi.org/10.1101/2021.02.15.429783; this version posted February 16, 2021. The copyright holder for this preprint (which was not certified by peer review) is the author/funder, who has granted bioRxiv a license to display the preprint in perpetuity. It is made
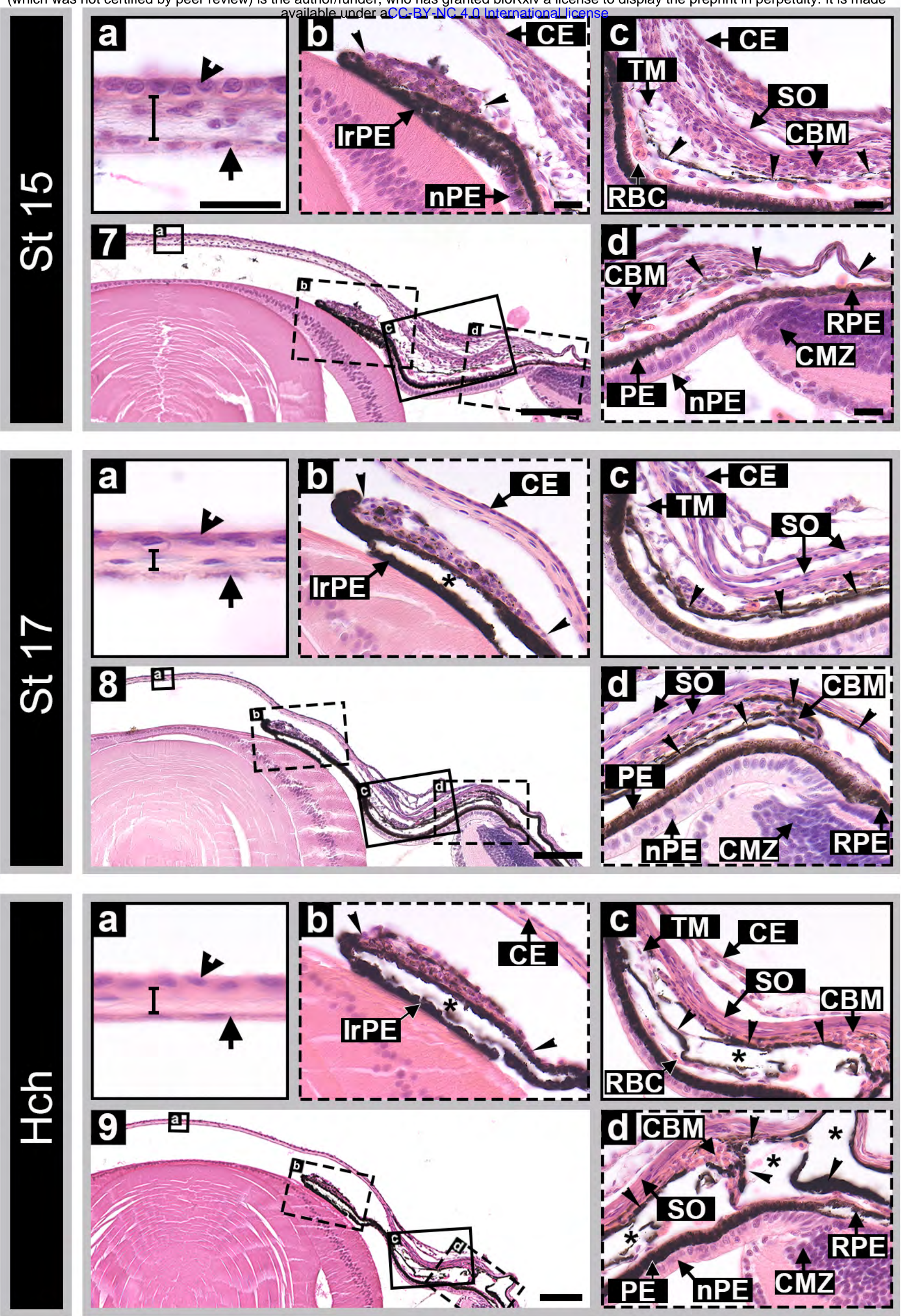


\section{St 14 \\ St 15 \\ St 17 \\ Hch \\ Adt}

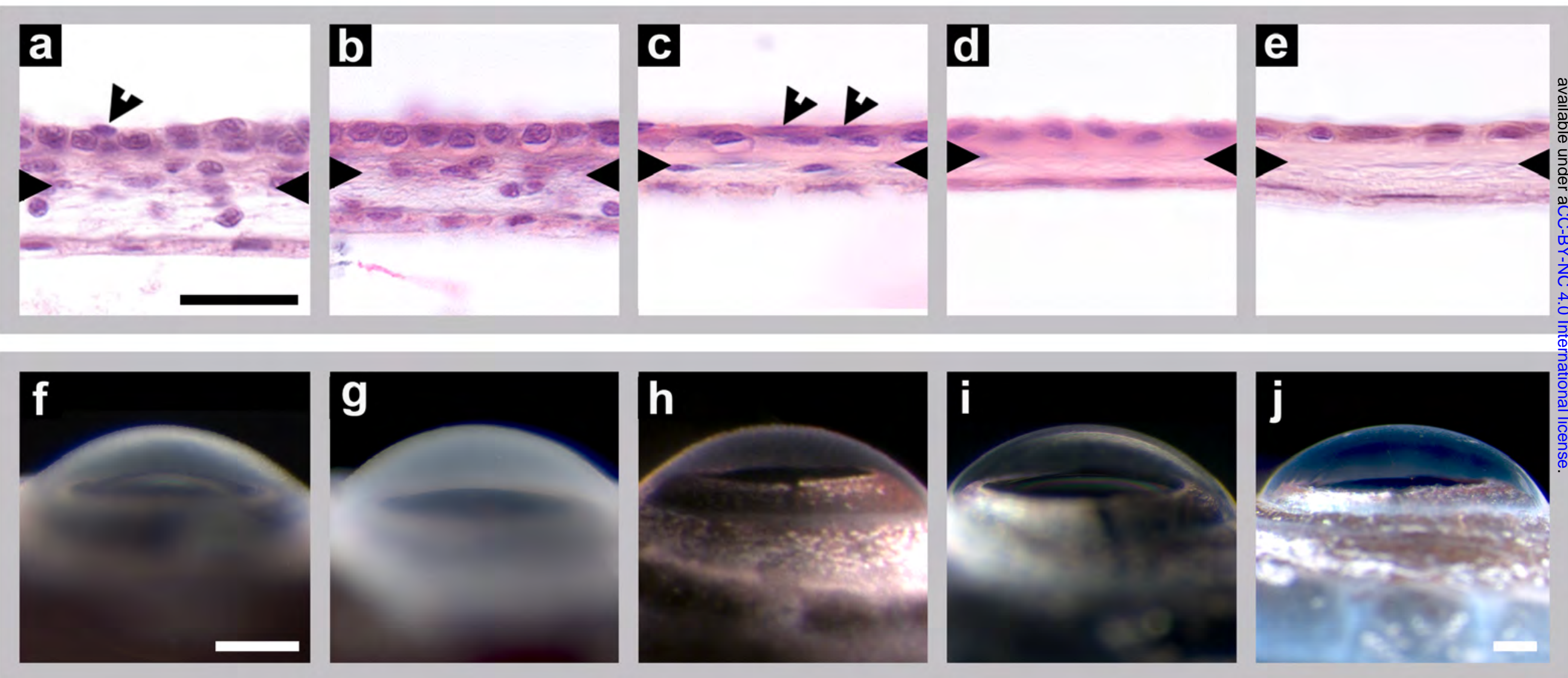


Figure 1 bioRxiv preprint doi: https://doi.org/10.1101/2021.02.15.429783; this version posted February 16, 2021. The copyright holder for this preprint
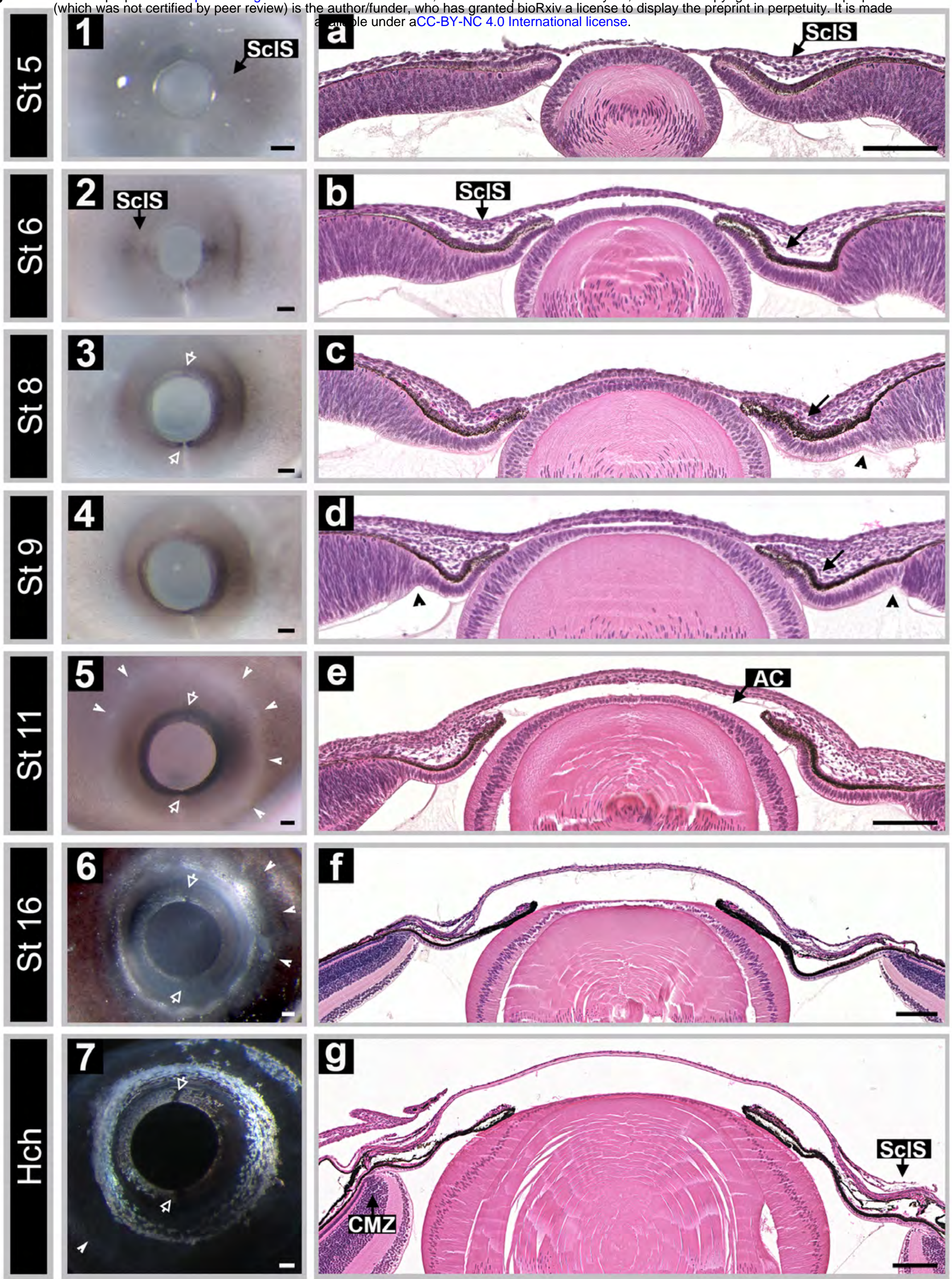